\title{
AEROACOUSTIC PERFORMANCE OF SCALE
}

\section{MODEL SONIC INLETS}

by John M. Abbott

Lewis Research Center

Cleveland, Ohio 44135

TECHNICAL PAPER to be presented at

Thirteenth Aerospace Sciences Meeting sponsored by the American Institute of Aeronautics and Astronautics

Pasadena, California, January 20-22, 1975 


\section{Abstract}

Tests were conducted in a low-speed wind-tunnel to evaluate the inflight aeroacoustic performance of severai single-snd multiple-passage sonic inlets. Takeoff and approach geometries were tested, and the effects of inlet $1 i p$ and diffuser design were determined. Results indicate that the singlepassage geometries, in particular a cylindrical centerbody takeoff geometry and a bulb-shaped centerbody approach geometry, provide the highest level of aeroacoustic performance. Increasing inlet lip contraction ratio extends the maximum incidence angle for attached 1 ip flow, while increasing inlet diffuser length results in higher total pressure recovery for a given amount of notse suppression.

\section{Introduction}

Aircraft engtne nolse radiated forward through the inlet can be reduced by accelerating the engine airflow to sonic or near-sonic velocity in the inlet throat. (1-7) Engine noise reduction is desirable whenever the aircraft is near the ground, that is, at both takeoff and approach. Because the engine alrflow at approach can be much less than at takeoff, it is necessary to provide a means of varying the inlet throat area to maintain sonic or near-sonic throat velocity at both conditions. This variation in geometry can be accomplished in many ways including the translation of variously shaped centerbodies, annular rings, and vanes and the expansion of centerbodies and cowl walls.

In this paper, results of an investigation to evaluate the aeroacoustic performance of several sonic inlet takeoff and approach geometries are presented. Two takeoff geometries were tested: (1) cylindrical centerbody; and (2) bulb-shaped centerbody. Four approach geometries were tested: (1) bulb-shaped centerbody; (2) annular ring; (3) radial vanes; and (4) step diffuser.

For a complete evaluation of a sonfc inlet geometry, many factors must be considered. These include: inlet georetry aerodynamic and acoustic performance; the feasibility of Integrating the takeoff geometry and the approach geometry into a complete sonlc inlet system; the implementation of actuation and control systems; relative weight; resistance to foreign object damage and the ability to incorporate anti-icing systems. It is not within the scope of this paper to conduct a systematic evaluation of all these factors since many are mechanical design considerations best suited for study during specific engine inlet development activities. Hence, in this paper, the inlet geometry evaluation is limited to the consideration of the relative aerodynamic and acoustic performance of various techniques used to provide a variation in inlet throat area.
At takeof $E$, where full engine thrust is required, the inlet geometry should provide the desirable level of acoustic suppression with a high level of total pressure recovery and a level of total pressure distortion acceptable to the fan. At approach, the acoustic suppression should be obtained again with a level of distortion acceptable to the fan, however, a high level of total pressure recovery is not as important because of the reduced level of engine thrust required during approach.

In addition to evaluating the performance of the different techniques for providing a variation in throat area, a determination of the effects of inlet internal lip shape and diffuser length on sonic inlet performance is also reported. Inlet 1 ip shape is a particularly $1 \mathrm{~m}-$ portant consideration for sonic inlets intended for powered-1ift short-haul aircraft applications. For this type of aircraft, high local incidence angles are encountered on the inlet lower lip as a consequence of the high upwash angle flow field generated by the powered-lift engine-wing system. (8) It is important that the airflow remain attached to the inlet lip with these high inlet incidence angles in order to avoid any reduction in total pressure recovery and increase in total pressure distortion due to lip flow separation.

Inlet diffuser length is an important consideration because the desire to keep the inlet as short as possible is in conflict with the high inlet flow Mach number changes (large diffuser area ratios) necessarily involved with sonic inlets. Th1s is most evident at approach where the engine airflow (and fan face Mach number) is lowest and yet the throat Mach number must be high in order to obtain the acoustic suppression. The diffuser area ratio is smaller at takeoff because of the higher inlet weight flow, however, it 1s still larger than that for a conventional inlet where the throat Mach number is considerably lower.

The inlets tested were deslgned to provide choked inlet flow at takeoff and approach weight flows typical for proposed shart-haul poweredlift aircraft $(100 \%$ and $78 \%$ of $\mathrm{f}$ an design weight flow). The relatively high approach weight flow is a consequence of the engine being used to supply both thrust and lift during the aircraft approach.

The inlets were tested at freestream velocities of 0 and 45 meters per second and inlet incidence angles from 0 to 50 degrees. These values are representative of flight conditions for shorthaul powered-1ift aircraft during takeoff and approach. Data presented include inlet total pressure recovery, total pressure distortion, diffuser exit total pressure distribution and acoustic suppression. 
Symbols

a

A DE

A TH $_{\text {TH }}$

b

BPF

D

$D_{\text {DE diffuser exit diameter }}$

$\mathrm{D}_{\mathrm{TH}} \quad$ cow1 throat diameter

$\mathrm{h}$

$\mathrm{L}_{\mathrm{D}}$

L

MH

$P_{1}$

$P_{1, a v}$

$\left(\mathrm{P}_{1, \mathrm{av}}\right)_{\mathrm{c}}$

Po

$\mathrm{P}_{\mathrm{s}}$

$r_{\text {HL }}$

$\mathrm{r}_{\mathrm{TH}}$

v

$\% \dot{W}_{D}$

$\mathbf{x}$

a

$(\triangle S P L)_{B P F}$

$\lambda_{\text {MAX }}$

$\psi$

throat flow area parameter, eq. (1)

diffuser length

cowl length

throat Mach number exit radius

surface static pressure

radius at highlight

radius at throat

freestrean veloctty hub at diffuser exit ellipse semi-major axis of internal 11p

diffuser exit flow area

ellipse semi-minor axis of internal lip

blade passing frequency

inlet total pressure distortion

flow passage height at diffuser exit

total pressure at diffuser exit

area averaged total pressure at diffuser

circumferentially averaged diffuser exit total pressure at constant

freestream total pressure

percent design corrected weight flow

axtal distance from cow1 highlight

radial distance measured outward from

inlet incidence angle, deg.

1/3-octave band sound pressure level reduction at blade passing frequency

maxintum diffuser wall angle, deg.

Inlet circumferential pasition, deg.

\section{Apparatus}

\section{Installation}

Shown in Figure 1 is a general layout of the test installation in the Lew is Research Center's $9-$ by 15 -foot $V / S T O L$ W1nd Tunnel. (9) The model was mounted on a turntable for testing at various incidence angles. Microphones were lacated upstream of the test section in a low-velocity reverberant area of the wind tunne1 to measure inlet radiated noise.
The test model conslsted of test inlets, a fan, exhaust ducting, and an exhaust noise muffier. The single stage, 13.97-centimeter-diameter, tip turbine driven fan was used both as a suction source and noise generator. The fan has 16 rotor blades resulting in a blade passing frequency of 9600 hertz at the fan design speed of $36,000 \mathrm{rpm}$. Design pressure ratio is 1.25 at a weight flow of $2.49 \mathrm{kilograms}$ per second. More detafls of the fan design are given in reference 10 . The fan exhaust was ducted out of the test section and Into a nofse muffler to permit an examination of only the noise being radiated forward through the inlet.

\section{Inlet. Des1gn}

The 1nlets discussed in this paper were designed to provide the necessary flow area reduction to choke at $100 \%$ and $78 \%$ of fan design weight flow; values estimated to be typical for short-haul powered-1ift aircraft during takeoff and approach. The corresponding diffuser area ratios, ${ }^{A_{D E}} / A_{T H}$, at takeoff and approach are 1.30 and 1.65 respectively. The sontc inlet takeoff and approach geometries tested are shown in Figure 2. The baseline geometry (cruise geometry) with a short spinner is also shown.

Note that the inlet geometries can be separated into two distinct groups depending on the number of throat flow passages. The radial vanes and annular ring concepts result in multiplepassage geometries as opposed to the other singlepassage geometries. The multiple-passage geometries are of interest because for a given rate of flow diffusion (change in flow area per unit length in one passage\}, the same overall area Increase can be accomplished in a shorter distance with a number of individual flow passages as opposed to a single flow passage. For a sonic inlet, where the airflow must be diffused from a throat Mach number of 1 to a fan face Mach number possibly as low as 0.5 at approach, this reduction in diffusion rate can result in a slgniflcant reduction in overall inlet length.

Some of the takeoff and approach geometries were tested with a number of cowls having different $11 p$ and diffuser designs. There were a total of four different cowl designs designated by the letters A, B, C and D. Important design parameters are given in Figure 3. Briefly, two lip designs were tested with lower lip contraction ratios, $\left(I_{\mathrm{HL}} / \mathbf{r}_{\mathrm{TH}}\right)^{2}$, of 1.30 and 1.44 . The 1.30 contraction ratio cowls ( $A$ and $B$ ) have symmetric lips with an elliptical internal lip shape defined by a semi-major axis to semi-minor axis ratio, $a / b$, of 2.0 . The 1.44 contraction ratio cowls ( $C$ and $D$ ) are asymetric, having a contraction ratio of 1.44 only at the lower lip with a smooth clrcumferential transition to a value of 1.30 at the sides which is then maintained over the entire upper half of the lip. When referring to cowls $\mathrm{C}$ and $\mathrm{D}$, the contraction ratio will be given as $1.44 / 1,30$ and the ellipse ratio as $2.0 / 2.9$.

Three different diffuser designs were tested having length to diameter ratios, $\mathrm{L}_{\mathrm{D}} / \mathrm{D}_{\mathrm{DE}}$, of 0.43 (cowl A); 0.61 (cow $B$ and $\mathcal{C}$ ); and 0.92 (cowl D). In all four cases, the nondmensional diffuser shapes were the same. Hence, by 
comparing data for, cow $1 \mathrm{~s} B$ and $C$, the effect of inlet lip design can be determined with the same diffuser design. By comparing data for cowls A and $B$ and ther cowls $C$ and $D$, the effect of inlet diffuser length can be determined with the same lip design.

\section{Instrumentation and Data Reduction}

Aerodynamic data. As indicated in Figure 4 inlet aerodynamic instrumentation consisted of diffuser exit total pressure probes ( 8 rakes; 6 probes per rake) located at the centroid of equal flow areas and surface static pressure taps on the inlet cowls. The instrumentation was in place during the testing of all of the takeoff, approach, and baseline geonetries. The pressure measurements were used to calculate inlet total pressure recovery, total pressure distortion, inlet weight flow and surface static-to-total pressure ratios.

The total pressure distortion parameter presented is defined as:

$$
\mathrm{D}=\left[\frac{\mathrm{P}_{1, \max }-\mathrm{P}_{1, \mathrm{~m} 1 \mathrm{n}}}{\mathrm{P}_{1, \mathrm{av}}}\right]_{40}
$$

of the 48 total pressure measurements made at the diffuser exit, the 8 closest to the outer wall of the flow passage were not Included in the calculation. $P_{1, \max }$ and $P_{1, \text { min }}$ are the maximum and minimum values, and $\mathrm{P}_{1}$, av is the area-average of the remaining 40 tatal pressure measurements.

The inlet weight flow was computed from the total and static pressure measurements made at the diffuser exit. For this calculation, a calibration test was performed using a standard bellmouth inlet to determine the correction factor to be appiled to the computed diffuser exit weight flow (about $3 \%$ ). Inlet throat Mach number was computed from the calculated inlet weight flow and the inlet geometric throat area. It is presented only to a limited extent in this paper because of its sensitivity to any small errors in measured weight flow in the region of throat Mach number from 0.70 to 1.00 (e.g., a $1 \%$ error in weight flow reduces the calculated throat Mach number from 1.0 to 0.89 ).

Acoustic data. Noise data were taken with 0,6 -centimeter-diameter microphones located in the low velocity wind tunnel settling chamber upstream of the test section (Fig. 1). Wind screens were placed on the microphones to minimize tunnel airflow notse. The hardwalls of the wind tumel approximate a reverberant chamber eliminating any directional noise variation due to changing model incidence angle within the range of interest. The noise data were processed using a 1/3-octave band analyzer ( 4 second sample time).

Values of noise suppression in the 1/3-octave band containing fan blade passing frequency were computed by subtracting the sound pressure level for the particular sonic inlet geometry from the corresponding level obtained with the baseline geometry with the same inlet cowl. This subtraction was done at the same fan speed, freestream velocity and incidence angle for the sonic inlet and the baseline geometries.

The procedure 1s illustrated in Figure 5, where 1/3-octave band sound pressure leve1 at the blade passing frequency is plotted agalnst fan speed for the baseline geometry and a sample sonic inlet geometry at static conditions and at a freestream velocity of 45 meters per second with an inlet incidence angle of 0 degree. The figure indicates that at stat1c conditions, the sonic inlet provides noise suppression down to at least the limiting static background level of about 49 dectbels. With freestream velocity there is no reason to expect that the inlet would not continue ta provide noise suppression down to this level. However, the operating tunnel background noise level is higher than the static background noise level and masks any reduction in noise level below about 60 decibels. The fact that the amount of inlet notse suppression for the sonic inlet. geometry does not quite reach the background noise limits is a consequence of noise being radiated from other sources at the model other than the inlet, such as the model support structure and the rear nolse muffler.

In the presentation of all the acoustic suppression data, the maximum amount of measurable noise suppression will be indicated. It should be remembered that if an inlet geometry shows this amount of suppression it may be actually providing much more suppression, and there may also be variations in suppression below this level that cannot be observed.

\section{Test Procedure}

The test procedure consisted of setting freestream velocity, inlet diffuser exit static pressure (weight flow) and varying inlet incidence ang1e. The diffuser exit static pressure was then changed (by changing fan speed) and the variation in incidence angle was repeated. Aerodynamic data were taken at incidence angles of $0^{\circ}$, $20^{\circ}, 30^{\circ}, 40^{\circ}$ and 50 degrees. Acoustic data were taken only at inlet incidence angles of $0^{\circ}, 20^{\circ}$, and 40 degrees.

\section{Resu1ts and Discussion}

\section{Performance of Takeoff Geometries}

During takeoff, where maximum thrust is required, it is desirable to have a high value of total pressure recovery and a value of total pressure distortion acceptable to the fan. For this reason, in comparing the two takeoff geometries, the highest total pressure recovery and lowest total pressure distortion for a given amount of nolse suppression is used as an aeroacoustic figure of merit.

Comparison of geometries. In Figure 6, inlet total pressure recovery and total pressure distortion for the two takeoff geometries with cowl $B$ are shown as a function of inlet noise suppression at the fan blade passing frequency. The data are shown for a freestream velocity of 45 meters per second at an inlet incidence angle of 0 degree. The maximum welght flow values are noted in the figure. As discussed previously, the maximum amount of noise suppression is limited by the wind tunnel background level as indicated in the figure. 
The data indicate that over the range of noise suppression values, the cylindrical centerbody geometry provides a higher level of total pressure recovery and lower level of total pressure distortion than the bulb-shaped centerbody geometry. At an inlet weight flow of $97.1 \%$ of design, about 21. decibels of measurable suppression at the blade passing frequency were obtained with a total pressure recovery of 0.99 and a total pressure distortion of 0.01 for the cylindrical centerbody take off geometry. The inlet geometry is choking at a weight flow slighty less than the design value ( 97\%). This is a result of a nonuniform velocity profile in the inlet throat and a reduction in the throat flow area due to surface boundary layer growth.

The 1ncrease in distortion and decrease in recovery encountered beyond the initial choke point is a consequence of supercritical operation of the inlet. In this region, shocks and boundary layer-shock interactions accur in the vicinity of the throat which result in the increase in total pressure losses.

The significantly lower pressure recoverles encountered with the bulb-shaped centerbody takeoff geometry are a result of greater total pressure losses occurring in the vicinity of the outer wall. An examination of the Iip surface static pressures indicated that higher lip surface Nach numbers were occurring with this geometry as compared to the cylindrical centerbody geometry. Apparently, the extension of the bulbshaped centerbody forward out of the inlet, resulted in a change in the cowl lip surface velocities which adversely affected the total pressure recovery.

Although it is not shown in this paper, a comparison of the two takeof $f$ geometries at static conditions and a freestream velocity of 45 meters per second with inlet incidence angles up to $40^{\circ}$ indicated no significant change in the relative performance of the two geometries. Therefore, the effect of inlet incidence angle and freestream velocity on aeroacoustic performance will be shown only for the cylindrical centerbody geometry.

Cylindrical centerbody geometry. Shown in Figure 7 is the variation of total pressure recovery and distortion with noise suppression at the blade passing frequency. Data are shown at a freestream velocity of 45 meters per second and Inlet incidence angles of $0^{\circ}, 20^{\circ}$, and $40^{\circ}$ along with data taken at static conditions. Data polnts are not shown for supercritical inlet operation.

First, by comparing the static data to the freestream velocity data at $0^{\circ}$ inlet incidence angle, it appears that there is no significant change in inlet performance as a consequence of introducing freestream veloc1ty. Increasing inlet incidence angle from $0^{\circ}$ to $20^{\circ}$ at a freestream velocity of 45 meters per second results in little change In aeroacoustic performance. However, at $40^{\circ}$ inlet incidence angle and at inlet wei ${ }^{\circ}$ ht flows corresponding to levels of noise suppression greater than about 7 decibels, inlet recovery decreases abruptly and inlet distortion increases accordingly. This sudden increase in total pressure loss occurred simultaneously with the formation of local regions of flow separation followed quickly by reattachment (separation bubbles) on the inlet lower 11 p as was evident from an examination of the surface static pressure measurements. (The formation of these separation bubbles is dependent on inlet size, i.e., Reynolds number and local curvature. It is possible that this 1ip flow behavior may not be encountered with a full scale inlet.)

It is interesting to note that even though the increase in inlet Incidence angle to $40^{\circ}$ degrades aerodynamic performance, the maximum amount of measurable nolse suppression is still attained. However, as noted in an earlier discussion, it is possible that the inlet acoustic performance has been affected, but the effects may be masked by the wind tunnel notse background level. Increasing inlet incidence angle further to $50^{\circ}$ (data not shown) resulted in complete flow separation from the inlet lower lip.

Total pressure contours at the diffuser exit are also shown in Figure 7 for data points $\mathrm{K}$, $\mathrm{L}$, and $M$ at inlet incidence angles of $0^{\circ}, 20^{\circ}$, and $40^{\circ}$, respectively. A data point at an inlet incidence angle of $30^{\circ}$ at about the same inlet weight flow is also shown. At $0^{\circ}$ inlet incidence angle, the distribution is circumferentially uniform with the total pressure losses occurring near the flow passage walls. Increasing inlet. incldence angle to $20^{\circ}$ results in a larger region of low total pressure in the lower portion of the inlet. However, the overall pressure recovery remalns unaffected. The distribution at $30^{\circ}$ inlet incidence angle shows a further expansion of the region of low total pressure in the lower portion of the inlet but again, the recovery remains unchanged $(0.986)$. At $40^{\circ}$ incldence angle there is a further increase in the size of the low total pressure region in the lower portion of the inlet coinciding with the appearance of flow separation bubbles on the Inlet lower lip. Hence, increasing inlet incidence angle results in a progressive increase in inlet circumferential distortion.

Noise spectra are shown in Figure 8 for a freestream velocity of 45 meters per second and inlet incidence angles of $0^{\circ}, 20^{\circ}$, and $40^{\circ}$ (data points $K, L$, and $M$ in Fig: 7). A spectrum for the baseline geonetry is also shown to indicate the noise level generated by the $f a n$ at the same rotational speed without sonic inlet noise suppression. The data show that for inlet incidence angles of $0^{\circ}, 20^{\circ}$, and $40^{\circ}$, the maximum amount of noise suppression (down to the background level) occurs at nearly all the 1/3-octave band center frequencies.

In summary, with the cylindrical centerbody geometry, at a value of inlet weight flow ( 97\% of design) that provided the maximum measurable noise suppresston, increasing inlet incidence angle from $0^{\circ}$ to $30^{\circ}$ at a freestream velocity of 45 meters per second, resulted in a progressive expansion of a low total pressure region in the lower portion of the inlet at the outer wall. The overall inlet pressure recovery remalned unchanged. At $40^{\circ}$ inlet incidence angle, a reduction in inlet recovery and increase in distortion occurred simultaneously with the formation of flow separation bubbles on the inlet lower 1ip, however, the maximum measurable amount 
of noise suppresston was st111 attained.

\section{Performance of Approach Geometries}

The problem of dectding which geonetry provides the best aeroacoustic performance is more difficult for the approach geometries than for the takeoff geonetries. As noted previously, at takeoff where full engine thrust is required, it is desirable to have a high level of inlet total pressure recovery. However, at approach the engine is not operating at full thrust and a high value of total pressure recovery may not be as important. The required approach thrust level can be obtained with a lower inlet pressure recovery by operating the engine at a higher rotational speed. Hence, in evaluating the inlet approach geometries, it should be remembered that the inlet recovery may not be the most important consideration and that other aerodynamic performance indicators such as diffuser exit total pressure distribution and the character of the total pressure distortion (circumferential or radial) may be of more importance. Because the importance of many of these other inlet performance indlcators is dependent on the particular engine or fan installation, they will not be considered in the comparison of inlet approach geometries. Instead, the highest level of recovery and lowest level of distortion, for a given level of noise suppression, will again be used as the aeroacoustic figure of merit.

Comparison of geometries. Shown in Figure 9 are the inlet total pressure recovery and distortion as a function of blade passing frequency noise reduction at a freestream velocity of 45 meters per second and an 1nlet incldence angle of $0^{\circ}$ For the four approach geometries (bulbshaped centerbody with cowl B; annular ring with cowl D; radial vanes with cowl $C$; and step diffuser with cowl B). It was not possible to compare each of the inlet geometries with the same cowl design. The annular ring geometry was designed to be used only with the long diffuser of cowl $\mathrm{D}$. The radial vane geometry was tested w1th both cowls $B$ and $C$, however, the acoustic data from the cowl $B$ test was unavallable. The step diffuser geometry was tested only with cowl B. It is felt, however, that at these particular conditions of freestream velocity and inlet incidence angle $\left(45 \mathrm{~m} / \mathrm{sec}, 0^{\circ}\right)$ that the relative performance of each of the approach geometries with cowls $\mathrm{B}, \mathrm{C}$, or $\mathrm{D}$ would not change significantly. This will be demonstrated in subsequent discussions of the effect of lip and diffuser design.

The data of Figure 9 indicate that the single flow passage bulb-shaped centerbody approach geometry provides the highest level of recovery and lowest level of distortion at all levels of inlet nolse suppression. This same result was found at all conditions of freestream velocity and inlet incidence angle. With 19 decibels of suppression at the blade passing frequency, the tatal pressure recovery is 0.961 and the total pressure distartion is 0.14 . Note that this level of suppression is occurring at a value of inlet welght flow $(77 \%)$ slightly less than the choking design value for the approach conditions ( $78 \%)$ due to the smaller throat area resulting from surface boundary layer bulldup and a nonuniform velocity profile in the throat.
The discussion will now proceed with a more detailed examination of the bulb-shaped centerbody geometry and a separate discussion of some interesting results for the other three geometries.

Bulb-shaped centerbody geometry. Shown in F1gure 10 is a plot of total pressure recovery and distortion against nolse suppression at the blade passing frequency for the bulb-shaped centerbody geometry at static conditions and at a freestream velocity of 45 meters per second with inlet incidence angles of $0^{\circ}$ (repeated from Fig. 9), 20 , and 40 degrees.

First, a comparison of the static data and the data obtained at a freestream velocity of 45 meters per second and an inlet incidence angle of $0^{\circ}$, shows a decrease in inlet aeroacoustic performance resulting from the introduction of freestream velocity. Increasing inlet incidence angle from $0^{\circ}$ to $20^{\circ}$ results in little change in aeroacoustic performance. At $40^{\circ}$ inlet incidence angle, the inlet naise suppression approaches the maximum measurable value, however, there is a continued decrease in total pressure recovery and increase in total pressure distortion. The surface static pressure measurements on both the cowl surface and the centerbody surface did not indlcate that any flow separation occurred at $40^{\circ}$ inlet incldence angle. Although the data are not shown, the lip flow was completely separated at $50^{\circ}$ inlet incidence angle.

Data points at $0^{\circ}, 20^{\circ}$ and $40^{\circ}$ inlet incidence angle where the inlet flow was choked (about 20 decibels of suppression) are labeled with the letters $P, Q$, and $R$. Total pressure contours at the diffuser exit are shown for each of these points in Figure 10 . At $0^{\circ}$ inlet incidence angle, data point $\mathrm{P}$, the distribution is axisymetric with the highest losses occurring in the hub region. This accounts for the general reduction in recovexy and increase in distortion over the values presented for the cylindrical centerbody takeoff geometry (Fig. 7). Increasing inlet incidence angle to $20^{\circ}$ and $40^{\circ}$ (data points $Q$ and $R$ ) results in a redistribution of the losses to the lower portion of the inlet but in this case, in the region of the hub. The recovery decreases from 0.961 to 0.944 from $0^{\circ}$ to $40^{\circ}$ incidence angle. This is in contragt to the cylindrical centerbody takeoff geometry where the redistribution of losses centered in the lower portion of the inlet but in the region of the outer wall (Fig. 7).

Figure 11 shows that the noise suppression for the bulb-shaped centerbody geometry occurred across the entire frequency range. Data are shown at inlet incidence angles of $0^{\circ}, 20^{\circ}$, and $40^{\circ}$ (data points $P, Q$, and $R$ ) along with a spectrum for the baseline geometry with the fan runing at the same rotational speed.

In sutnmary, with the bulb-shaped centerbody approach geometry, at a value of inlet weight flow ( 77\% design) that provided the maximum level of suppression, 1ncreasing inlet incidence angle from $0^{\circ}$ to $40^{\circ}$ at a freestream velocity of 45 meters per second resulted in a reduction in total pressure recovery from 0.961 to 0.944 and an expansion of a low total pressure region in the lower portion of the inlet at the hub. A 
nolse suppression, of about 20 dectbels at the blade passing frequency was attained at incidence angles of $0^{\circ}, 20^{\circ}$, and 40 degrees.

Annular ring. As was indicated in Figure 9, the annular ring approach geonetry appeared to provide respectable aeroacoustic performance up until a suppression level of about 9 dectbels beyond which no further notse suppression could be obtained. A typical noise frequency spectruro at this maximum level of suppression is shown in Figure 12 along with a spectrum for the baseline geotietry with the fan runing at the same rotational speed. The data indicate that over a large percentage of the frequency range, this inlet geometry actually has higher noise levels than the baseline geometry. There is some suppression at the blade passing frequency, but the level is not nearly down to the tunnel background leve1. There are a number of possible sources for this acoustic behavior including vibration of the ring itself. It seems more likely, however, that increased fan nolse generation due to the wakes from the annular ring and support struts may be somehow propagating forward through the inlet.

Radial vane. The radial vane data shown $i_{n}$ Figure 9 indicated that inlet noise suppression was obtained with this geometry, however, the total pressure losses were relatively high with a rather rapid drop in recovery at about the 7 decibel value of suppression. This rapid $1 n-$ crease in total pressure losses is attributed to passing through the drag rise region for this particular alrfoil section (NACA 632 A015). In this region, attempts to Increase inlet airflow by increasing fan speed, result in Increases in inlet total pressure losses which tend to off set the effect of increased fan speed. After passing through this region, inlet airflow again increases and the high levels of acoustic suppression are finally approached as the inlet chokes. This result suggests that by designing this type of inlet with an airfoil section having a smaller thickness-to-chord rat1o, the aeroacoustic performance should improve. With a finer airfoil section, a higher drag rise Mach number would result and a greater inlet weight flow, and hence, a greater amount of acoustic suppression, could be obtained before the drag rise total pressure losses were encountered.

An examination of the total pressure distribution at the diffuser exit, shown in Figure 13, suggests another source of inlet total pressure losses for the radial vane geometry. As the figure indicates, increasing inlet alrflow results in the total pressure losses becoring increasingly dominant in the hub region. This can be explained by the fact that the axlal diffugion rate through the vanes in a given annular flow area is greater in the hub region than in the tip region because of the constant thickness of the vanes (higher solidity at the hub). This higher diffusion rate then results in higher losses at the hub. A solution to this problem would be to taper the vanes in thickness so they were thinner in the hub region providing equal axial flow diffusion rates across the entire flow passage.

Step diffuser. As has been noted in the discussion of the results for each of the single- passage geometries, increasing inlet incldence angle results in an increase in the extent of the total pressure losses in the lower portion of the diffuser exit. This in turn means that the circumferential total pressure distortion is changing and increasing with higher inlet incidence angles. Such loss patterns may pose a potential problem to the engine fan designer. The design philosophy adopted with the step dfffuser approach geometry was to force the total pressure losses to occur at the tip around the entire circumference. Hopefully, with increasing inlet incidence angle, the losses would remain circumferentially uniform thus eliminating the changes in circumferential distortion at the expense of a constant, known radial distortion. It was recognized that the total pressure recovery would be low, but as noted previously, for an approach inlet geometry this may not be a critical factor.

As Figure 9 indicated, the total pressure recovery for the step diffuser geometry was the lowest of all those tested, but comparable inlet. noise suppression was provided. Add1tional data (not shown) indicated that suppression was occurring across the entire frequency range and freestream veloc1ty and inlet incldence angle had practically no effect on aeroacoustic performance. Shown in Figure 14 are total pressure distributions at the diffuser exit at inlet incidence angles of $0^{\circ}$ and $50^{\circ}$ and a freestream velocity of 45 meters per second. The figure indicates that the total pressure distribution did not change significantly with increasing inlet incldence angle. The circumferential variation of total pressure remained unchanged and essentially zero over the inlet incidence angle range from $0^{\circ}$ to 50 degrees.

\section{Effect of Lip Design}

The effects of inlet 11p design will be discussed first for the cylindrical centerbody takeoff geometry and then some comments will be made with regard to the bulb-shaped centerbody approach geometry.

Cylindrical centerbody takeoff geometry. In Figure 15 , aeroacoustic results are shown for cowls B and C (Ffg. 15(a) and (b)) having lip contraction ratios of 1.30 and $1.44 / 1.30$ and Internal lip ellipse rattog of 2.0 and $2.0 / 2.9$ respectively. Inlet total pressure recovery and inlet noise suppression at the blade passing frequency are plotted agalnst percent design corrected weight flow for static conditfons and at a freestream velocity of 45 meters per second with inlet incidence angles of $0^{\circ}$ and 40 degrees. Inlet total pressure recovery is also presented for an inlet incidence angle of $50^{\circ}$ (noise data were not taken at this condition).

Aerodynamically, it is apparent from comparing the total pressure recovery data of F1gure 15(a) and (b) that increasing inlet lower lip contraction ratio from 1.30 to 1.44 results in an increase in the maximutm inlet incidence angle obtainable before lip flow separation occurs. With the 1.30 contraction ratio inlet, at a $40^{\circ}$ inlet incidence angle at high values of inlet welght flow, the appearance of lip separation bubbles is evident from the slight drop in 
recovery. At $50^{\circ}$ inlet incidence angle, the recovery data indicate complete flow separation from the inlet lower 1ip. With the 1.44 lower lip contraction ratio inlet, the inlet lip flow remains completely attached ip to an inlet incidence angle of at least 50 degrees. At static conditions and with freestream velocity at inlet incidence angles less than $40^{\circ}$, the inlet pressure recovery is about the same for the two lip designa.

The noise suppression data shown in Figure 15 indicate two major differences between the acoustic performance of the inlet with cowls $B$ and $C$. First, with cowl $c$ (having an internsl lip ellipse ratio of $2.0 / 2.9$ ) the inlet does not provide the maxitnum amount of measurable noise suppression while the inlet with cow1 B $(\mathrm{a} / \mathrm{b}=$ 2.0) does. This is particularly evident at static conditions where the inlet with cowl B provides 33 decibels of suppression while with cowl $C$, on 1 y 14 decibels. Spectra for these two data polnts (maximum static noise suppression) are shown in Figure 16 and indicate this loss in suppression capability is occurring at all frequencies above about 5000 hertz.

Secondly, Figure 15 shows that at inlet weight flows less than about $96 \%$ of design, operation of this inlet geometry with cowl $C$ resulted in an increase in fan noise generation (particular1y with freestream velocity) and is actually generating up to 10 declbels more notse than the baseline geometry (negative values of suppression).

An examination of the diffuser exit total pressure measurements of fers no obvious aerodynamic explanation for this inlet acoustic behavior with cowl $C$. However, the surface static pressure measurements on the inlet lip (not shown) do indicate the possible existence of a lip flow separation bubble near the highlight at the $\psi=180^{\circ}$ circumferential position $(a / b=2.9)$ at static conditions. With freestream velocity, the separated region appears to have been eliminated, however, with the limited number of surface static pressure measurements it cannot be determined for certain that this is the case. The increased likelihood for lip flow separation to occur with a larger ellipse ratio is discussed in reference 11 where it is shown that increasing internal lip ellipse ratio results in high rates of surface curvature. Th1s in turn leads to high surface velocities and unfavorable boundary layer conditions near the inlet highlight which may result in flow separation.

If a region of lip flow separation does indeed exist over the upper half of the cowl 1ip (where the internal lip ellipse ratio is 2.9 ), then this may offer an explanation for the acoustic behavior observed with inlet cowl $\mathrm{C}$. The separated 1ip flow may result in an increase in the fan source noise and may also form a region of lower flow velocity in the inlet throat providing a notse propagation path. Support is offered for this explanation by the results of reference 7 , where sonic inlets having internal lip ellipse ratios of $2.0,3.0$, and 4.0 were tested at static conditions. Acoustic spectra obtalned in that Investigation, with the cowl lips having ellipse ratios of 3.0 and 4.0 , were nearly identical to that shown for cowl $\mathrm{C}$ in Figure 16. The inlet cowl with an ellipse ratio of 2.0 (same as cowl B) provided complete acoust1c suppression. At full scale, the aerodynamic behavior described here may not occur and the inlet acoustic performance with cowl $C$ may Improve accordingly.

Bulb-shaped centerbody. Although data are not shown for the bulb-shaped centerbody approach geometry with cowl $C$, the apparent separation bubble was again evident on the inlet 1ip at the $\psi=180^{\circ}$ position $(a / b=2.9)$ at static conditions. The amount of nolse suppresston at the blade passing frequency was also liaited, although in this case to a higher value of 25 decibels out of a measurable 40 decrbels. With a freestream veloctty of 45 meters per second, the 11p flow separation was again apparently eliminated and in this case the amount of suppression obtained at inlet incidence angles of $0^{\circ}, 20^{\circ}$, and $40^{\circ}$ was nearly equal to the tunnel noise floor limit. Also, the increased fan noise generation evident with the cylindrical centerbody takeoff geometry with cowl $\mathrm{C}$ was not present. Hence, the acoustic performance of the bulbshaped centerbody approach geometry with cowl $\mathrm{C}$ was not adversely affected to the same degree as the cylindrical centerbody takeoff geometry. The reason for this change in Inlet performance is believed to be due to the reduced internal lip surface velocities encountered at the approach weight flow, as opposed to the higher weight flow at takeoff, which resulted in an overall improvement of the cowl 11 p performance. As with the cylindrical centerbody geometry, the increased liwer lip contraction ratio of cowl $\mathrm{C}$ resulted in an extension of the maximum inlet incidence angle for attached 1ip flow to at least 50 degrees.

In brief sumary, Increasing inlet lower lip contraction rat1o from 1.30 (cowl B) to 1.44 (cowl C) resulted in an increase in the maximum inlet inctdence angle for lip flow separation from $40^{\circ}$ to at least $50^{\circ}$ for the cylindrical centerbody takeoff geometry. 'However, the acoustic performance of this inlet geometry was adversely affected by the lip design of cowl $\mathrm{C}$ which had a lip contraction ratio of $1.44 / 1.30$ and an internal lip ellipse ratio of $2,0 / 2.9$. With the bulb-shaped centerbody approach geometry, cow1 C also provided attached inlet lip flow up to an inlet incidence angle of at least 50 degrees. The acoustic performance of this geometry at static conditions was again adversely affected by the lip design of cowl $\mathrm{C}$, however, with freestream velocity at all incldence angles, the suppression was comparable to that for cowl B.

\section{Effect of Diffuser Design}

The effect of inlet diffuser design will be discussed only for the cylindrtcal centerbody takeoff geometry. The same general results pertain to the bulb-shaped centerbody approach geometry.

Shown in Figure 17 is the effect of diffuser length on the aeroacoustic performance of the cylindrical centerbody takeoff geometry at a freestream velocity of 45 meters per second and an inlet incidence angle of $D$ degree. In Figure 17(a), cowls $A$ and $B$ are compared having 
the same inlet 11p shape with diffuser length-todiameter ratios, $\mathrm{L}_{\mathrm{D}} / \mathrm{D}_{\mathrm{DE}}$, of 0.43 and 0.61 respectively. In Figure $17(\mathrm{~b})$, cowls $C$ and $D$ are compared having the same Inlet lip shape (but different from cowls $A$ and $B$ ) with diffuser length-to-dlameter ratios of 0.61 and 0.92 .

The data of Figure 17 indicate a progressive improvement in inlet aeroacoustic performance as diffuser length is increased. The improvement is most striking in Figure 16(a) where cowl A with a diffuser length to diameter ratio of 0.43 provides 15 decibels of noise suppression with a total pressure recovery of 0.978 . Cow $1 \mathrm{~B}$, with a diffuser length-to-diameter ratio of 0.61 provides the same level of noise suppression but with a considerably higher recovery of 0.991 . The lower level of performance encountered with cowl $\mathrm{A}$ is attributed to a combination of higher total pressure losses due to the higher rate of flow diffusion and a reduction in the internal attenuation of the noise due to the shorter length. The shorter length results in fewer internal noise reflections where acoustic energy can be dissipated.

The comparison between the inlets having diffuser length-to-dlameter ratios of 0.61 and 0.92 , Figure $17(\mathrm{~b})$, shows a slight improvement in aeroacoustic performance as a result of increasing diffuser length, but not to the same degree as In Figure 17(a). At a nolse suppression level of about 15 decibels, cow $1 \mathrm{C}$ with a diffuser length-to-dlameter ratio of 0.61 has a total pressure recovery of 0.986 while $\operatorname{cow} 1 \mathrm{D}$, with a diffuser length-to-diameter ratio of 0.91 , has a recovery of 0.991 at the same level of suppression.

The relative effects of inlet diffuser length (shown in $\mathrm{Fig}, 17$ ) also occurred at static conditions and with freestream velocity at inlet incldence angles up to 40 degrees. Thus, increasing inlet diffuser length resulted in an improvement in inlet aeroscoustic performance. This improvement was most dramatic when diffuser length-to-diameter rat10 was increased from 0.43 to 0.61 .

\section{Performance of Composite Translating/Expanding} Centerbody Sonic Inlet

The results of the previous discussions have been combined in Figure 18 to provide the aerodynamic and acoustic performance of a complete sonic inlet system. In an actual application. the inlet would be operated by translating a cylindrical centerbody forward at takeoff to provide choked airflow. At approach, where the engine airflow is reduced, the centerbody would be expanded to provide the choked alrflow. Hence, the performance of the inlet can be constructed from a combination of the results for the cylindrical centerbody takeoff geometry and the bulb-shaped centerbody approach geometry. This combination of takeoff and approach geometries represents the highest level of inlet aeroacoustic performance, based on the highest recovery for a glven level of suppression, encountered in this investigation.

The performance data for the composite sonic inlet system shown in Figure 18 were obtained for the takeoff and approach geometries utilizing cow1 B. The Internal lip ellipse ratio of 2.0 provides good aeroacoustic performance of the inlet (as opposed to the 2.9 of cowl C). The diffuser length-to-diameter ratio of 0.61 also provides a high level of aeroacoustic performance. Only slightly better performance was obtained with the longer diffuser of cow $1 \mathrm{D}$ and the associated weight gain may negate this slight advantage.

The inlet 11p contraction rat1o of cowl $B$ is 1.30. At an inlet incidence angle of $40^{\circ}$, regions of local flow separation are encountered with this inlet lip resulting in a reduction in recovery and increase in distortion. Hence, for an aircraft installation where an inlet incidence angle of $40^{\circ}$ or more is anticipated, an increase in lip contraction ratio above 1.30 may be necessary. However, it is also possible that a full scale inlet with a contraction ratio of 1.30 may not encounter this flow separation at an inlet inc1dence angle of 40 degrees.

The data in Figure 18 are presented in a plot of inlet nolse suppression at the blade passing frequency and inlet total pressure recovery versus percent of fan design corrected weight flow. The freestream velocity is 45 meters per second and the inlet incidence angle is 20 degrees. Values of inlet throat Mach number are spotted on the curves, On the noise suppression curve, a horizontal line for the illustrative case of a constant 20 decibel noise suppression is drawn and the resulting values of inlet pressure recovery are established by the vertical Ifnes drawn in the figure. At takeoff, 20 decibels of suppression at the blade passing frequency are attained at an inlet weight flow of $97 \%$ of design with a total pressure recovery of 0.988 (the distortion is 0.01 from Fig. 7). At approach, the same level of suppression is attalned at an inlet welght flow of $77 \%$ of design with a total pressure recovery of 0.952 (the distortion of 0.19 from Fig. 10).

A very important sonic inlet design consideration is demonstrated by the data of Figure 18 . Note that with a constant inlet throat area, only slight changes in inlet weight flow will result in considerably larger changes in inlet notse suppression. For example, decreasing inlet weight flow from 77 to $76 \%$ of design flow results in a drop to suppression from 20 dectbels to 9 decibels for the bulb-shaped centerbody approach geometry. Hence, during aircraft operation, in order to maintain a prescribed level of inlet noise suppression, considering the possibility of small excursions in inlet weight flow, an active control system may be required to provide a continuous varlability of inlet throat area to malntain a constant throat velocity.

A continuous control of the inlet throat area would most likely be required for any sonic inlet geometry since this sensitivity of noise suppression to weight flow is basically a result of the increased sensitivity of throat Mach number to weight flow as the throat Mach number approaches 1,0 . Hence, the relative ease with which a continuous variation in inlet throat area can be accomplished is a very important criteria whlch must be considered in the complete evaluation of a sonic Inlet system. For example, small throat area variations accomplished by an axial translation of the bulb-shaped centerbody 
approach geonetry may be easier to accomplish than small throat area variations with the radial vane approach geometry.

\section{Sumsaary of Results}

Results of a wind tunnel investigation of the performance of a number of scale model sonic inlets indicated:

1. A single-passage cylindrical centerbody takeoff geometry provided the highest level of inlet pressure recovery for a given value of noise suppression over all conditions of freestream veloctty and inlet incidence angle, Lip flow separation bubbles encountered at an inlet incidence angle of $40^{\circ}$ did not affect the inlet noise suppression withtn the measurable 1 imits.

2. A single-passage bulb-shaped centerbody approach geometry provided a higher value of inlet pressure recovery for a given value of inlet noise suppression than the single-passage step ditfuser geometry or either of two multiplepassage geometries (annular ring and radial vane) over al1 conditions of freestream velocity and inlet incidence angle.

3. With the cylindrical centerbody takeoff geometry and the bulb-shaped centerbody approach geouietry, increasing inlet incidence angle resulted in an appaxent circumferential redistribution of inlet total pressure losses to the lower portiun of the diffuser exit.

4. Results for the radial vane approach seometry suggested that decreasing vane thicknessto-chord ratio and spanwise tapering of vane thickness would inprove the aeroacoustic performance of this geometry.

5. The step diffuser approach geonetry had a low level of pressure recovery, however, the circumferential distribution of total pressure at the diffuser exit (and hence the circunferential distortion) was unchanged with increasing inlet incidence angle.

6. With the cylindrical centerbody takeoff geometry, changing cowl lip design from a contraction ratio of 1.30 and internal lip ellipse ratio of 2.0 to values of $1.44 / 1.30$ and $2.0 / 2.9$ (asymmetric lip), extended the maximum inlet inc1dence angle limtt for separation of the lip flow from $40^{\circ}$ to at least 50 degrees. However, the high internal lip ellipse ratio of 2.9 apparently resulted in an increase in fan noise generation and a reduction in inlet noise suppression capability.

7. Increasing inlet diffuser length-todiameter ratio from 0.43 to 0.61 resulted in an increase in inlet pressure recovery at a given level of noise suppression. A further increase in length-to-diameter ratio from 0.61 to 0.92 improved aeroacoustic performance only slightly.

8. The sensitivity of inlet nolse suppression to small changes in inlet weight flow indicates the necessity for providing a continuous variation in inlet throat velocity. Hence, the ease to which a throat area variation can be accomplished with a given sonic inlet geometry is an important criteria that must be considered in the overall inlet evaluation.

\section{References}

1. Miller, B. A. and Abbott, J. M., "Aerodynamic and Acoust ic Performance of Two Choked-Flow Inlets Under Stat1c Conditions," TM X-2629, 1972, NASA.

2. Miller, B. A. and Abbott, J. M., "Low-Speed WindTunnel Invegtigation of the Aerodynamic and Accoustic Performance of a Translating Centerbody Choked-F1ow Inlet," TM X-2773, NASA.

3. Abbott, J. M., Miller, B. A. and Golladay, R. L., "Low-Speed Wind-Tunnel Investigation of the Aerodynamic and Acoustlc Performance of a Translating-Grid Choked-Flow Inlet, TM X-2966, 1974, NASA.

4. Chestnutt, D., "Nolse Reduction by Means of InletGulde-Vane Choking In an Axial-Flow Compressor," TN D-4682, 1968, NASA.

5. Klufber, F., Bosch, J. C., Demetrlck, R. W. and Robb, W. L., "Investigation of Nolse Suppression by Sonic Inlets for Turbofan Eng1nes," D6-40855, Ju1. 1973, Boefng Comerclal Alrplane Co., Seattle; Wash.; also CR-121126, 1973, NASA.

6. Klujber, F., "Results of an Experimental Program for the Development of Sonic Inlets for Turbofan Engines," AIAA Paper 73-222, Washington, D.C., 1973.

7. Groth, H. W., "Sonic Inlet Nolse Attenuation and Performance with a J-85 Turbojet Engine as a Nolse Source," AIAA Paper 74-91, Washington, D.C., 1974.

8. Albers, J. A., "Predicted Ipwash Angles at Engine Inlets for STOL Aircraft," TM X-2593, 1972, NASA.

9. Yuska, J. A., Diedrich, J, H, and Clough, N., "Lewts 9- by 15-Foat v/STOL Hind Tunne1," TM X2305,1971 , NASA.

10. "Ingtallation and Performance Data, Mode1 TD-652 5.5-Inch Tip Turbine Fan," Aug,, 1969, Technical Development Inc., Dayton, Ohio.

11. Albers, J. A. and Mtller, B. A., "Effect of Subcontc Inlet Lip Geometry on Predicted Surface and Flow Mach Number Distributions," TN D-7446, 1973, NASA. 


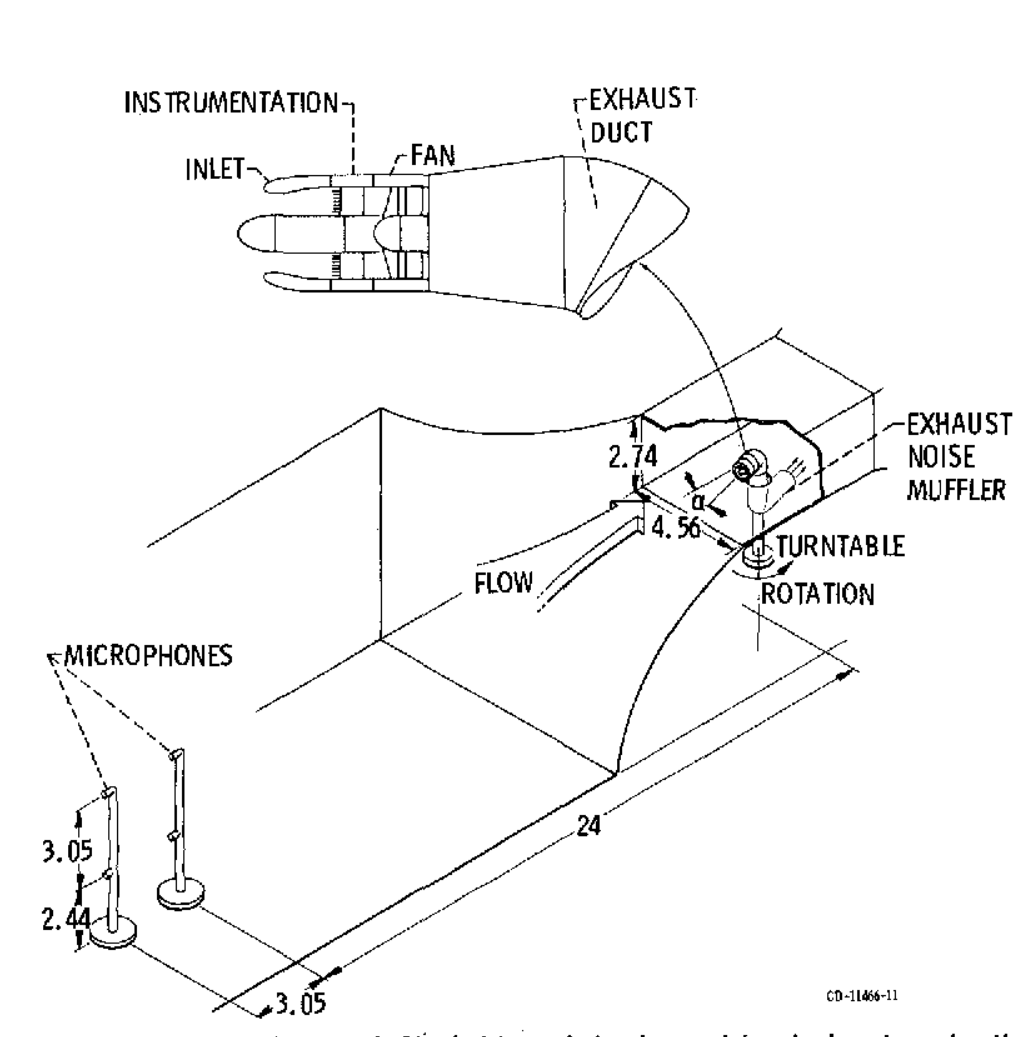

Figure 1. - Schematic view of VISTOL wind tunnel showing model and microphone locations. (All dimensions in meters.)

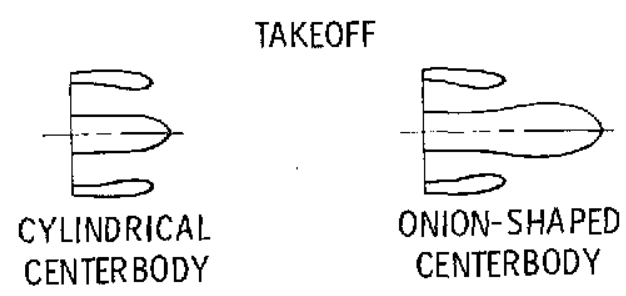

APPROACH
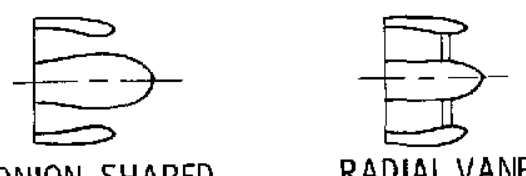

RADIAL VANE

ONION-SHAPED

CENTERBODY

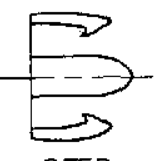

STEP

DIFFUSER

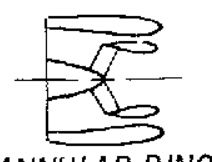

ANNULAR RING

BASELINE (CRUISE)

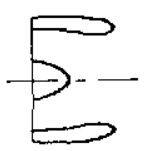

Figure 2. - Inlet geometries tested. 


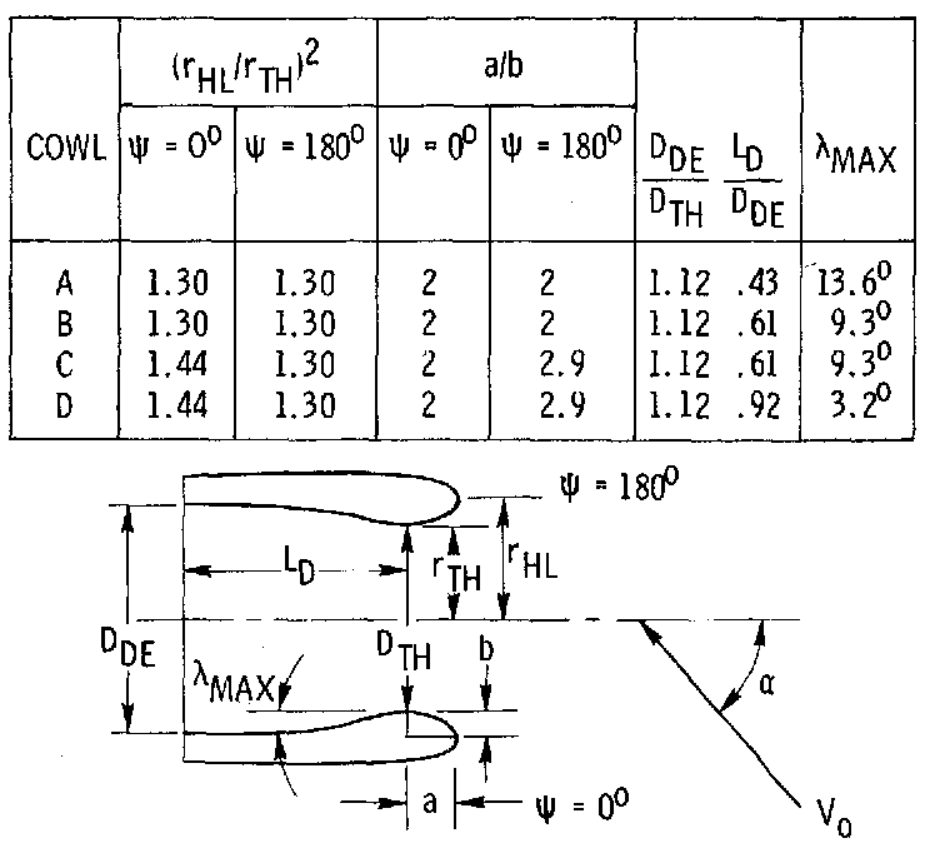

Figure 3. - Cowl geometries.

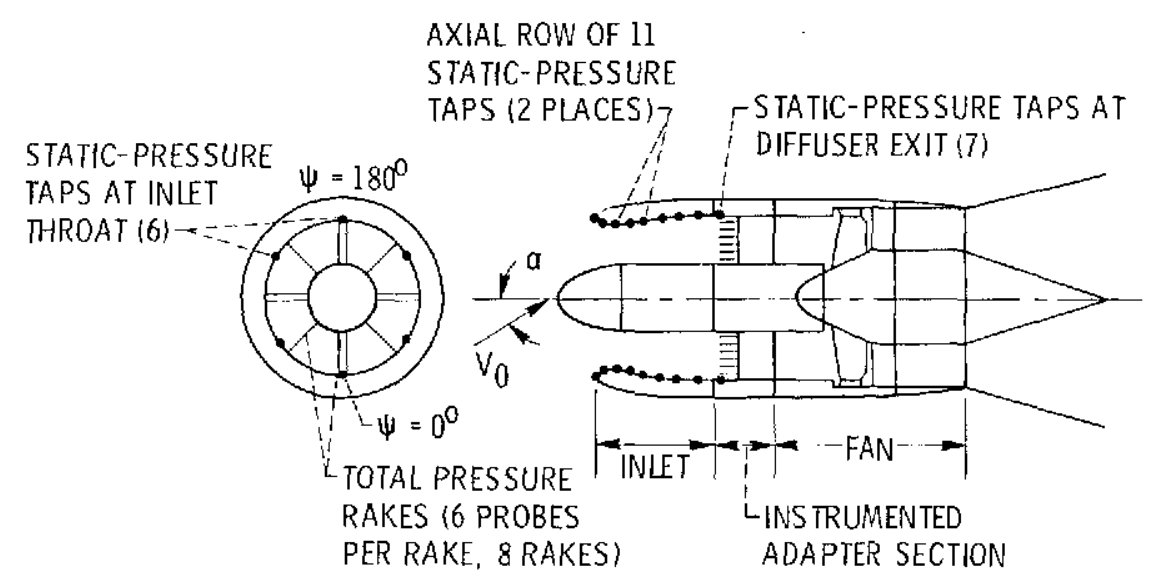

Figure 4. - Schematic view of test model showing location of instrumentation. 


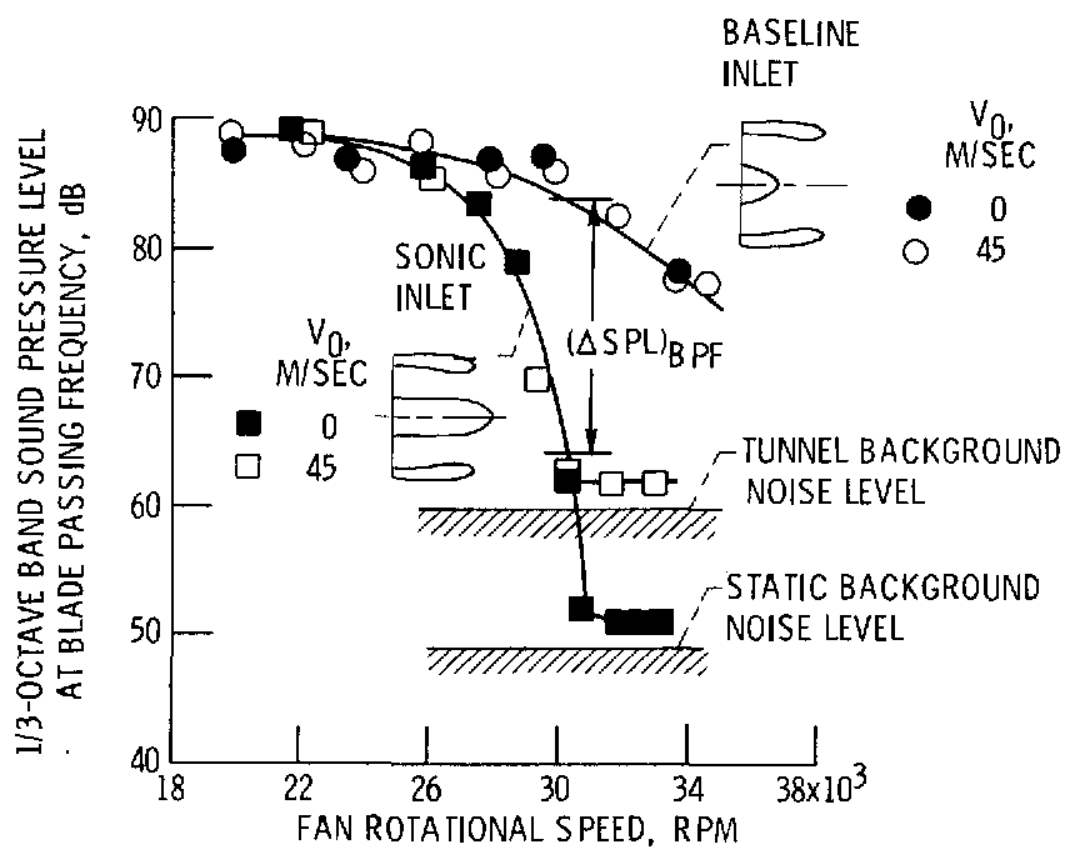

Figure 5. - Illustration of procedure used to determine noise suppression. $a, 0^{\circ}$.
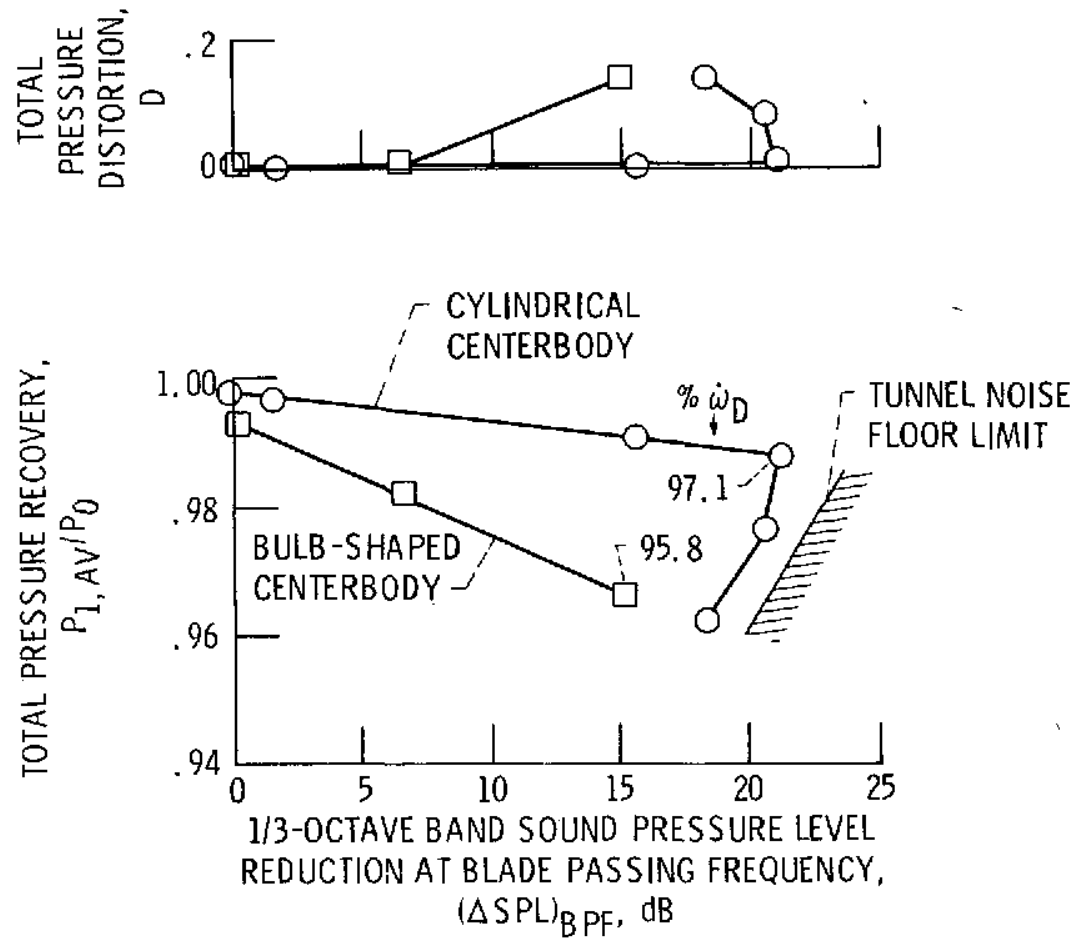

Figure 6. - Aeroacoustic performance of sonic inlet takeoff geometries. Cowl $B ; V_{0}, 45 \mathrm{~m} / \mathrm{sec} ; a, 0^{0}$. 


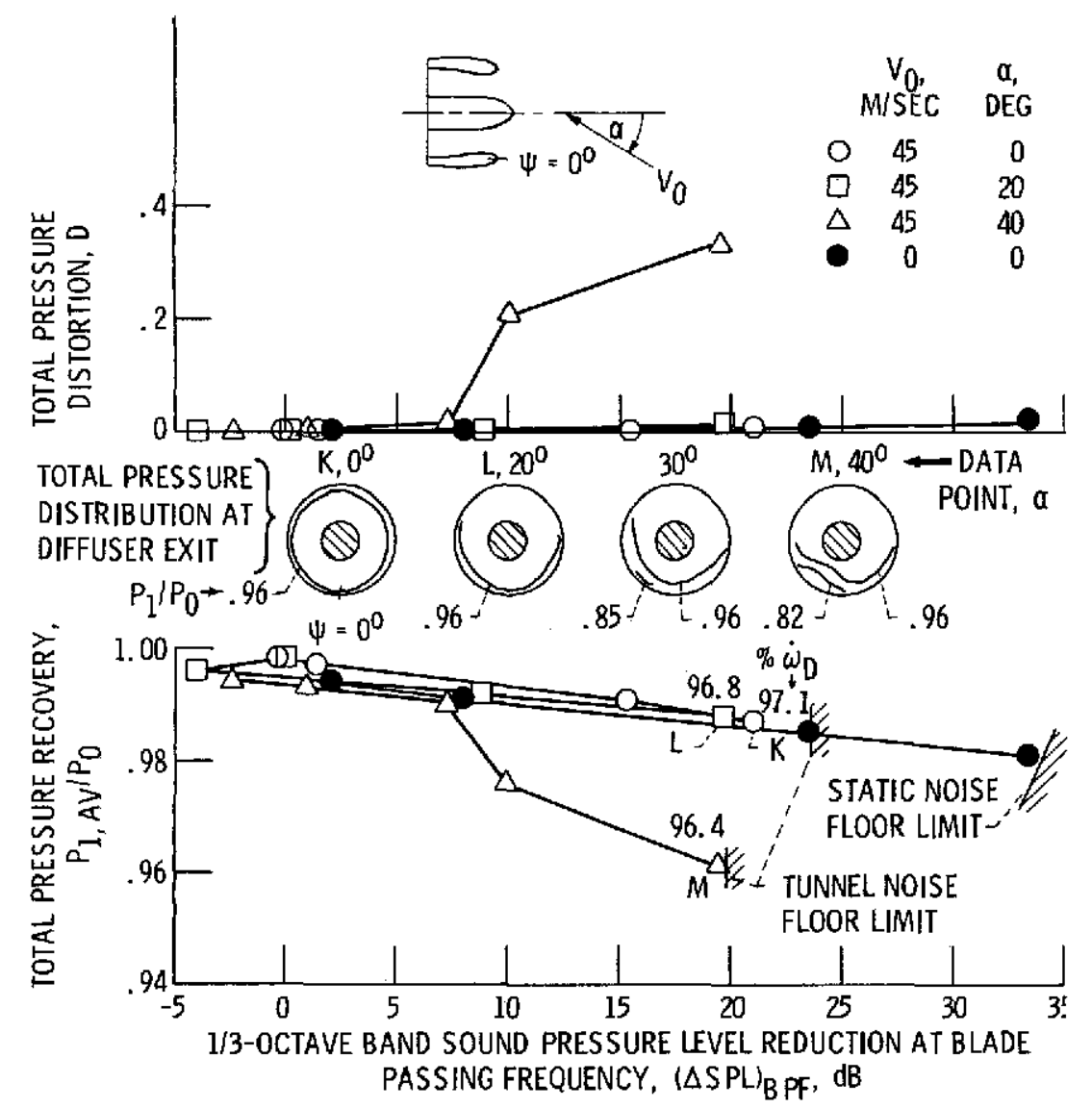

Figure 7. - Aeroacoustic performance of the cylindrical centerbody takeoff geametry. Cowl B.

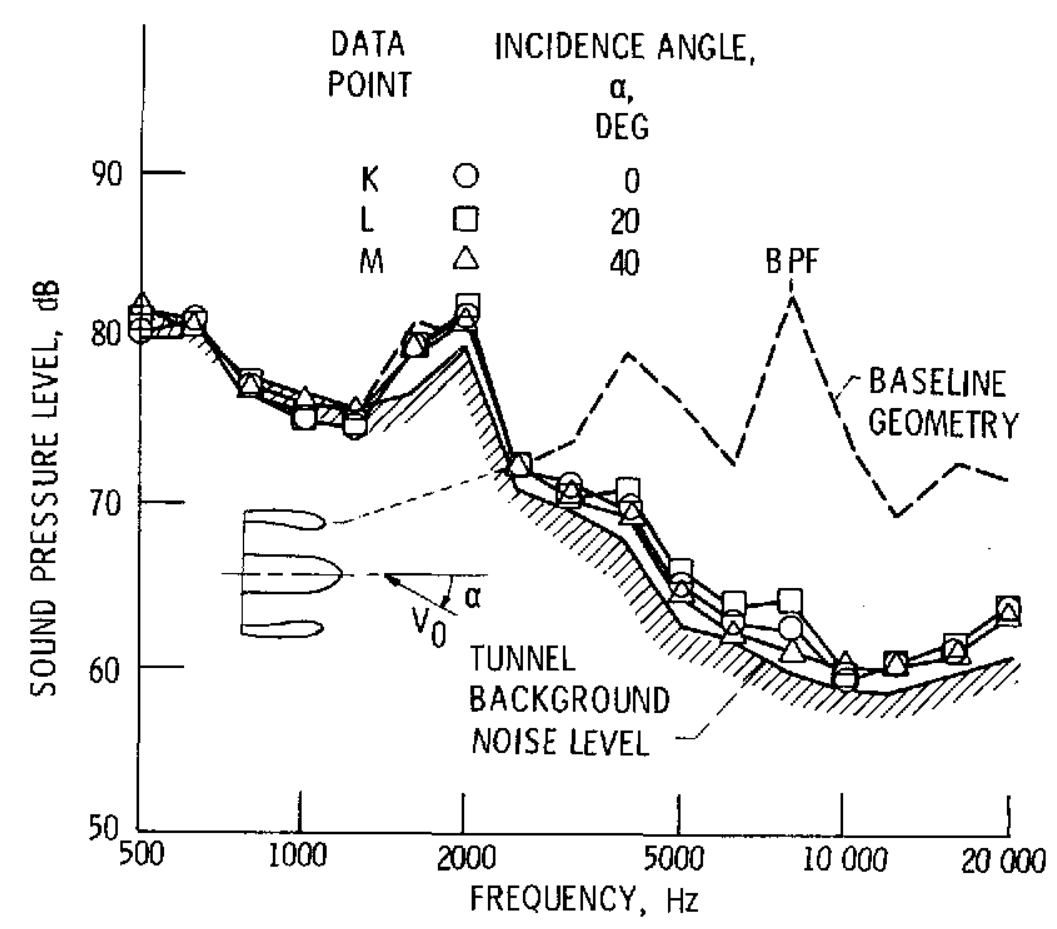

Figure 8. - Effect of incidence angle on acoustic spectra for cylindrical centerbody takeoff geometry. Cowl B; $V_{0}, 45 \mathrm{~m} / \mathrm{sec}$; $\% \dot{\omega}_{D} \simeq 97$. 


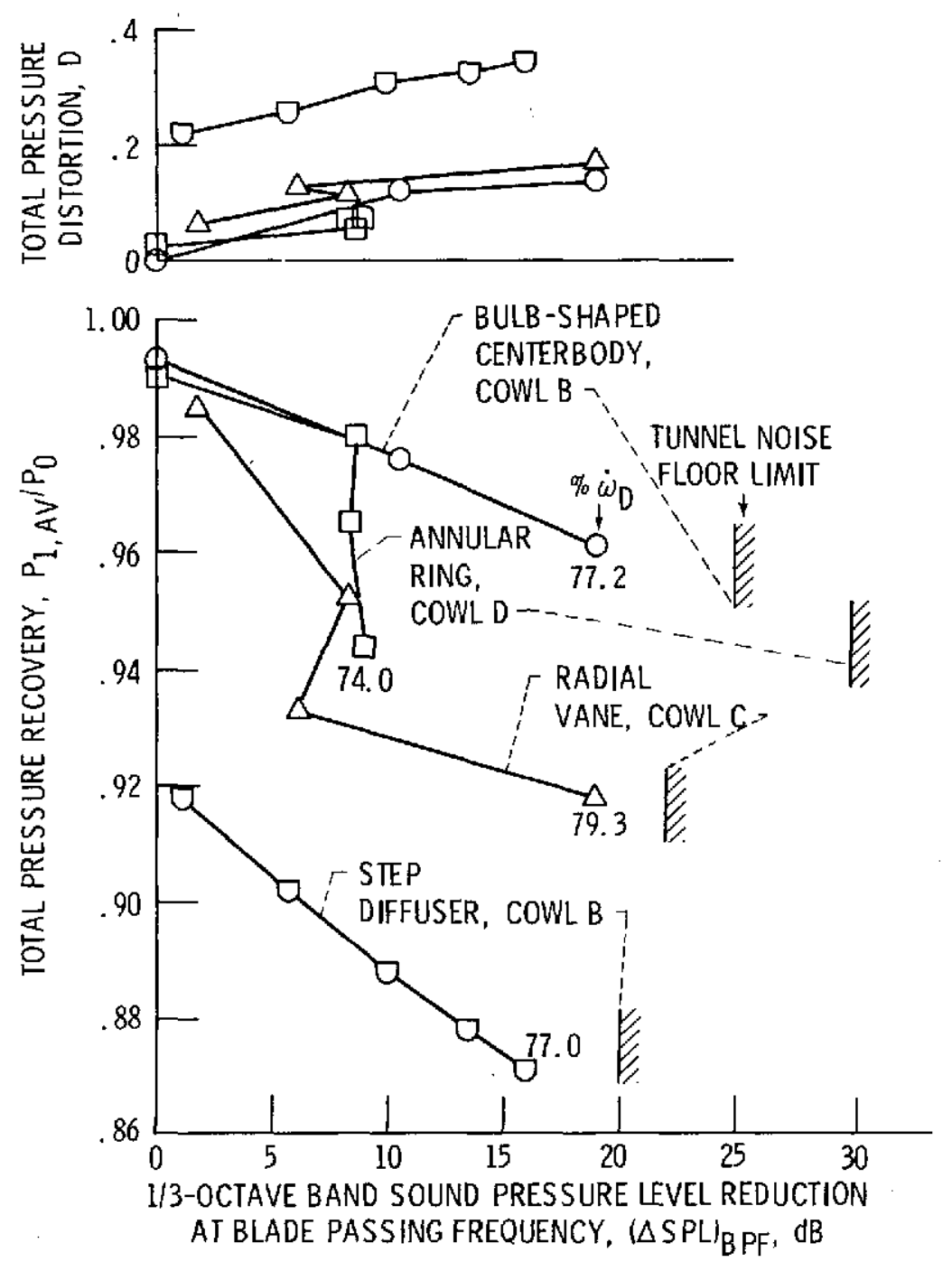

Figure 9. - Aeroacoustic performance of sonic inlet approach geometries. $V_{0}, 45 \mathrm{~m} / \mathrm{sec} ; \alpha, 0^{\circ}$.
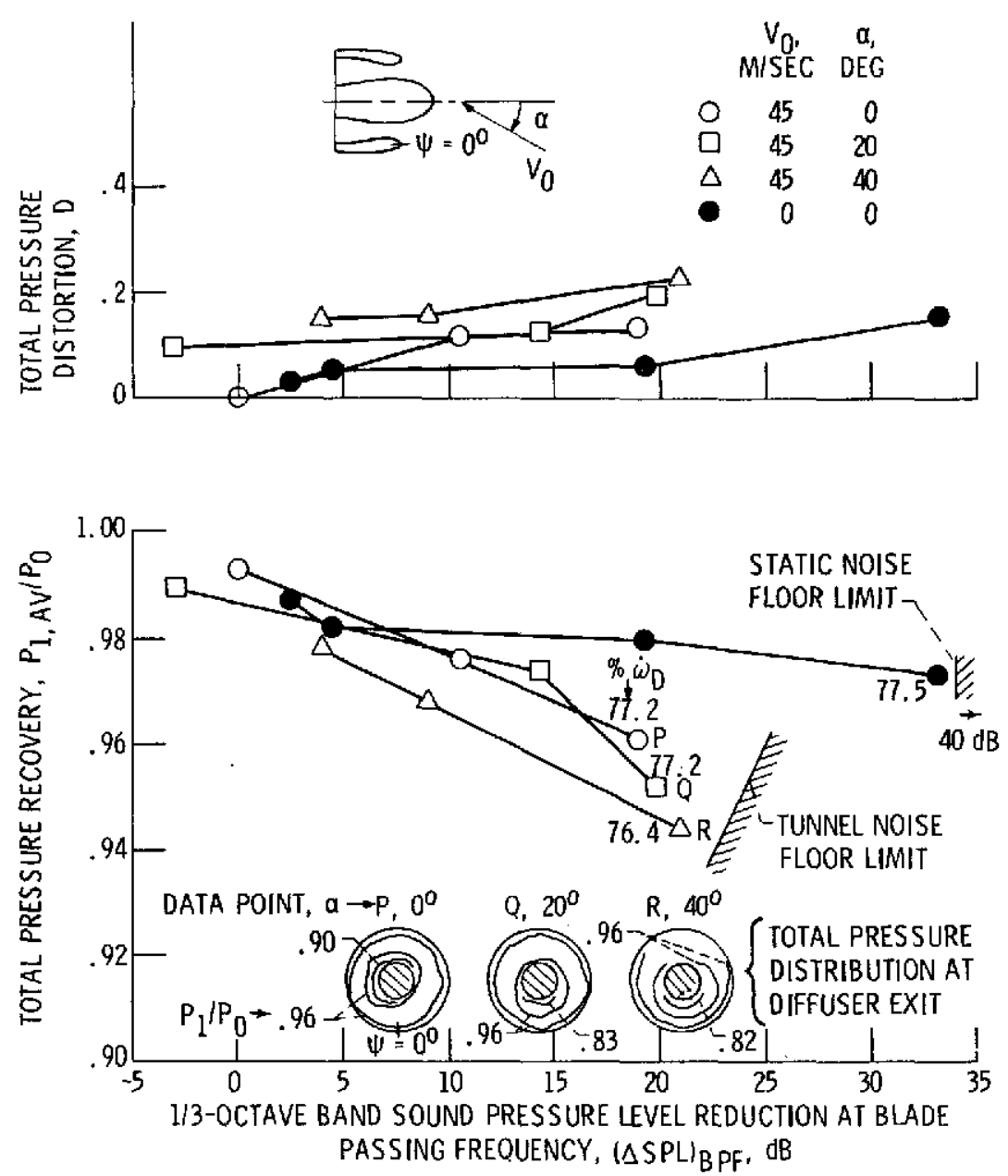

Figure 10. - Aeroacoustic performance of the bulb-shaped centerbody approach geometry. Cowl B. 


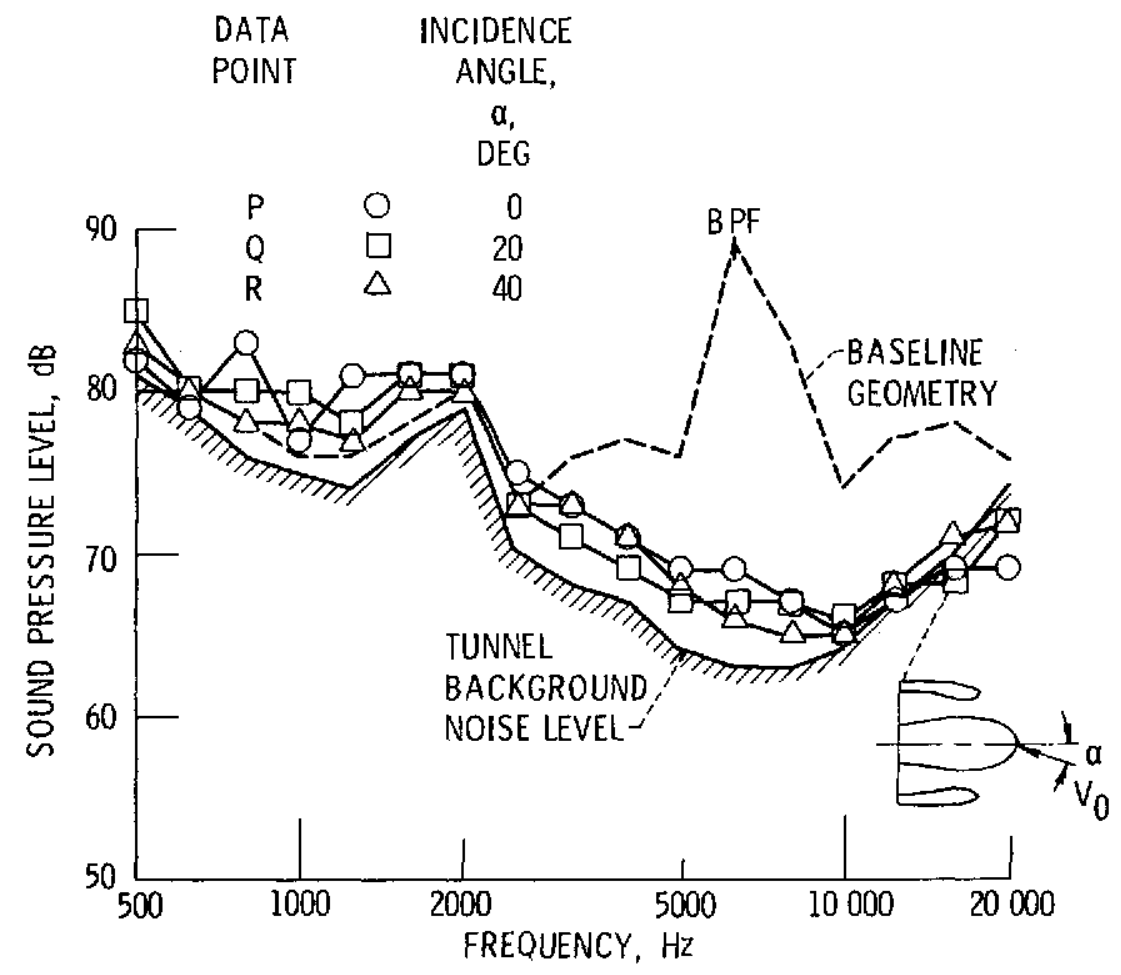

Figure 11. - Effect of incidence angle of acoustic spectra for bulb-shaped centerbody approach geometry. Cowl B; $V_{0}$. $45 \mathrm{~m} / \mathrm{sec}$.

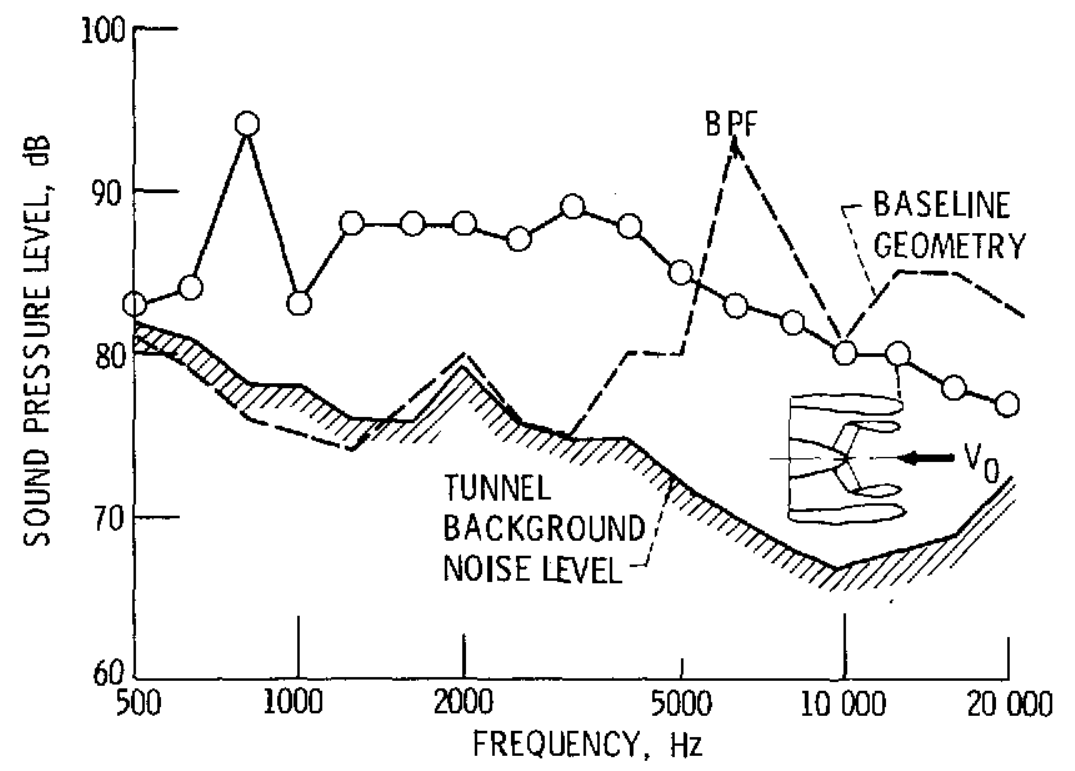

Figure 12. - Acoustic spectrum for annular ring approach geometry. Cowl D. $V_{0}, 45 \mathrm{~m} / \mathrm{sec} ; a, 0^{0} ; \% \dot{\omega}_{0}=74.0$. 


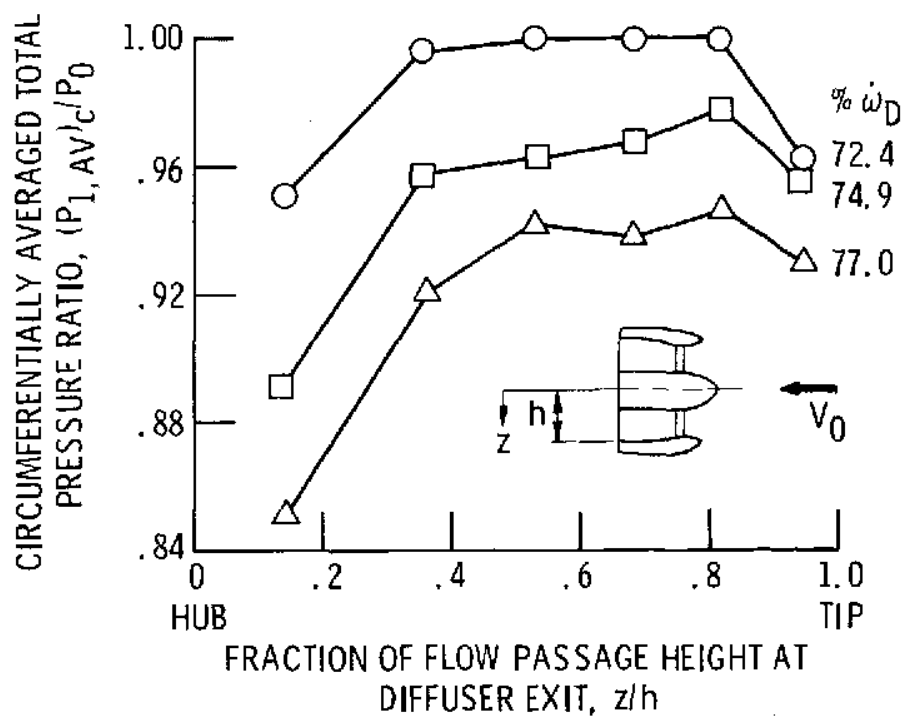

Figure 13. - Distribution of total pressure at diffuser exit for radial vane approach geometry. Cowl c. $V_{0}, 45 \mathrm{~m} / \mathrm{sec} ; \alpha, 0^{\circ}$.

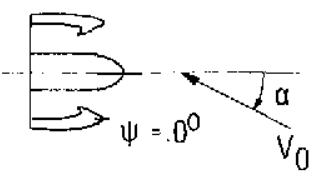

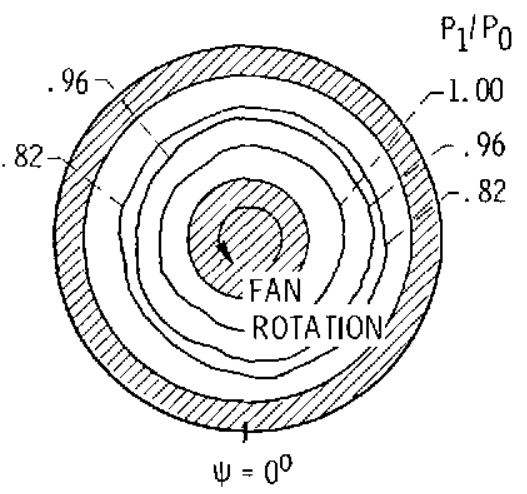

(a) $\alpha, 0^{0}$.

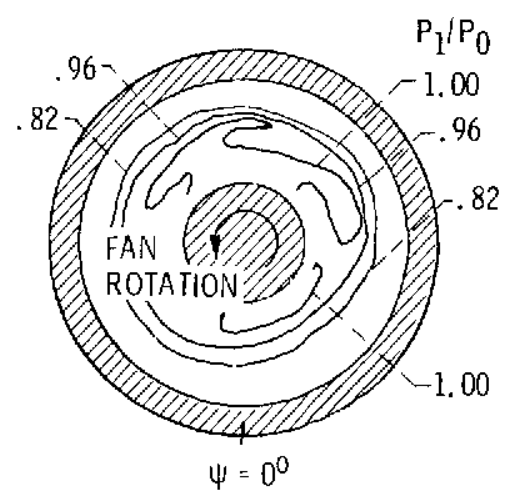

(b) a, $50^{\circ}$.

Figure 14. - Effect of incidence angle on total pressure distribution at diffuser exit plane for step diffuser approach geometry. Cowl B. $V_{0}$, $45 \mathrm{~m} / \mathrm{sec} ; \% \dot{\omega}_{D}, 77.0$. 

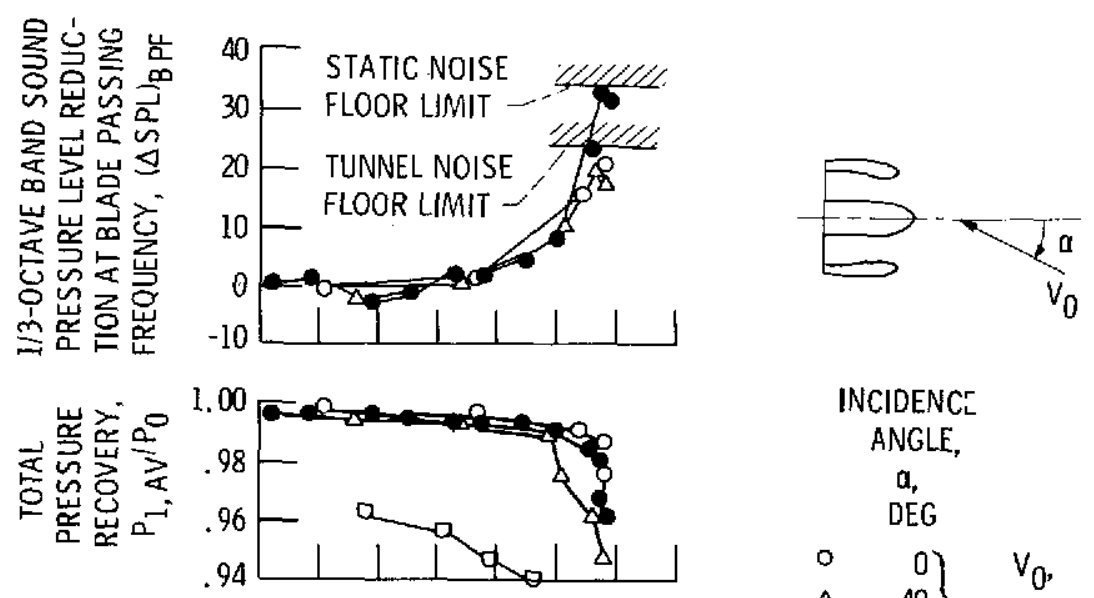

(a) COWL B; $\left(r_{H L} / r_{T H}\right)^{2}, 1.3 ; a / b, 2.0$.

$$
\begin{aligned}
& \text { INCIDENCE } \\
& \text { ANGLE, } \\
& \text { a, } \\
& \text { DEG } \\
& \left.\begin{array}{ll}
\circ & 0 \\
\Delta & 40 \\
0 & 50
\end{array}\right\} \begin{array}{c}
V_{0}, \\
45 \mathrm{M} / \mathrm{SEC}
\end{array}
\end{aligned}
$$
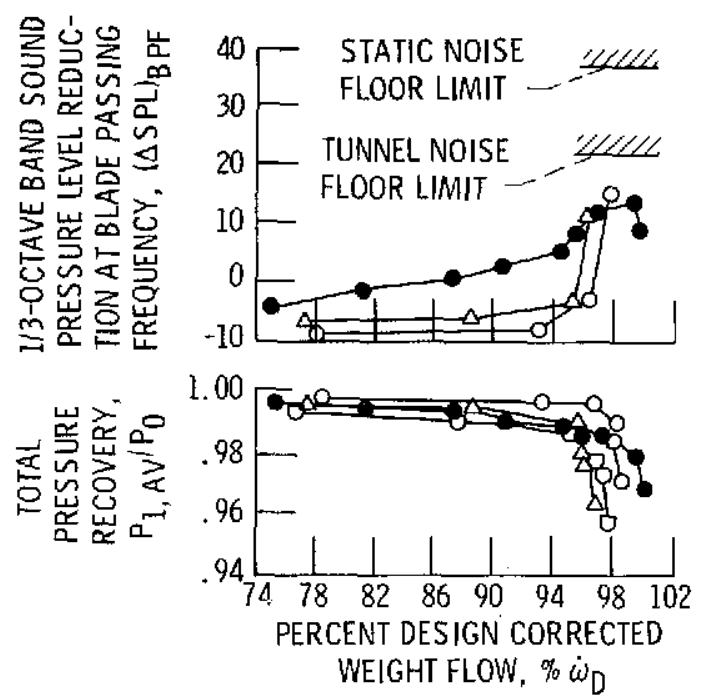

(b) COWL C; $\left(r_{\mathrm{HL}} / \mathrm{r}_{\mathrm{TH}}\right)^{2}, 1.4411 .3$; a/b, 2.0/2.9.

Figure 15. - Effect of lip design on the aeroacoustic performance of the cylindrical centerbody takeoff geometry. 
$\begin{array}{ccc} & \text { COWL } & \% \dot{\omega}_{D} \\ \text { 口 } & \text { C } & 99.4 \\ \text { O } & \text { B } & 96.9\end{array}$

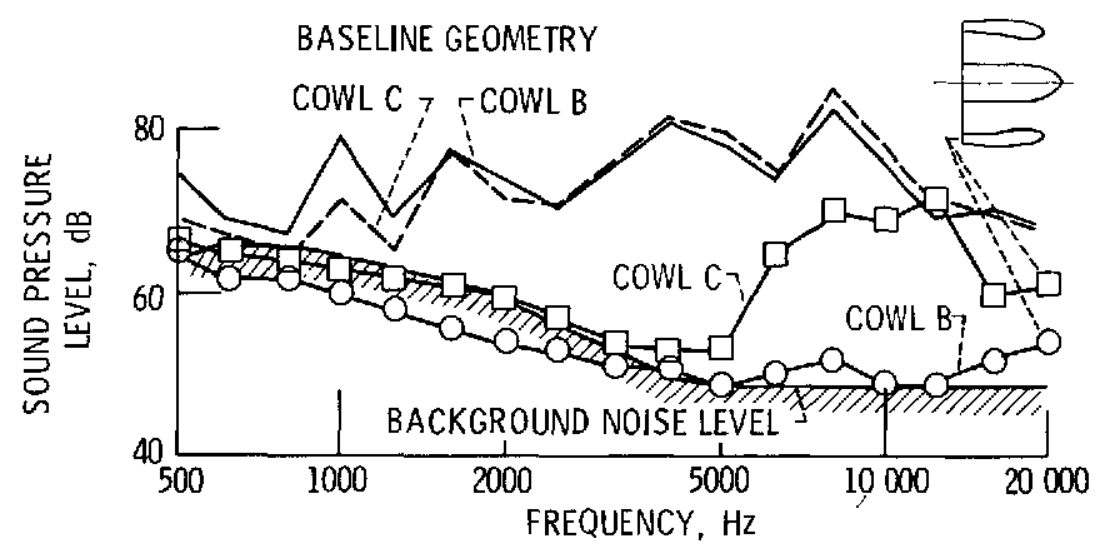

Figure 16. - Effect of internal lip ellipse ratio (a/b) on acoustic spectra at static conditions for cylindrical centerbody takeoff geometry. Maximum inlet weight flow.

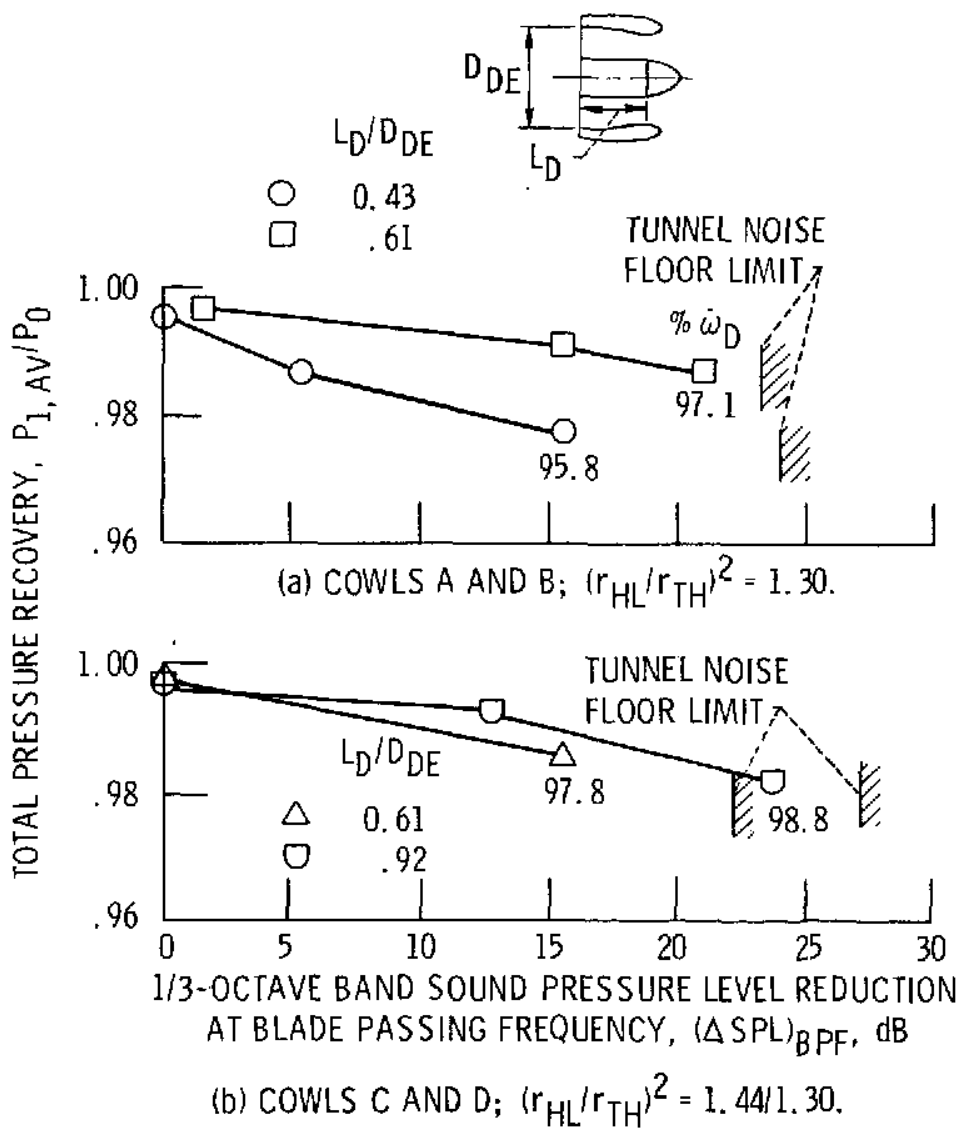

Figure 17. - Effect of cowl diffuser length on aeroacoustic performance of the cylindrical centerbody takeoff geometry. $V_{0}, 45 \mathrm{~m} / \mathrm{sec} ; \alpha, 0^{\circ}$. 


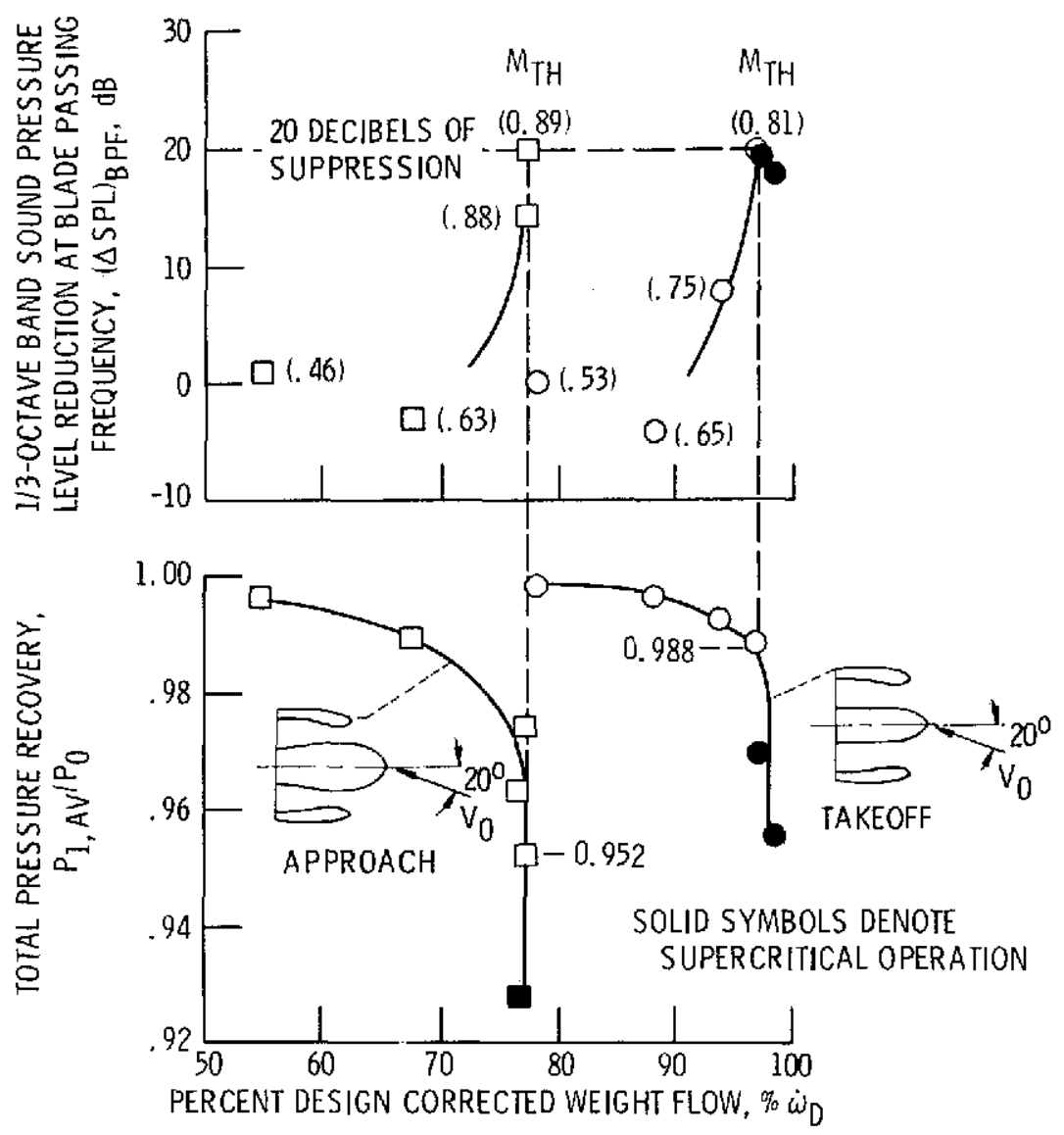

Figure 18. - Aeroacoustic performance of translatinglexpending centerbody sonic inlet at takeoff and approach. Freestream velocity, $45 \mathrm{~m} / \mathrm{sec}$; incidence angle, $20^{\circ}$. Cowl $\mathrm{B} ;\left(\mathrm{r}_{\mathrm{HL}} / \mathrm{r}_{\mathrm{TH}}\right)^{2}$, 1. 30; $L_{D} / D_{D E}, 0.61$. 